\title{
STUDY OF CHANGES IN OPPORTUNISTIC INFECTIONS AFTER ONE YEAR OF ANTIRETROVIRAL THERAPY IN HIV INFECTED PATIENTS IN A TERTIARY CARE CENTRE IN NORTH BENGAL
}

\author{
Biswadev Basu Majumdar1, Bapi Lal Bala², Apu Adhikary3, Jyotirmoy Pal', Saikat Datta ${ }^{5}$, Souvonik Mandal ${ }^{6}$, Avijit Moulick 7 , \\ Arunangshu Talukdar ${ }^{8}$ \\ 1D. M. Cardiology Post Doctorate Trainee, Nilratan Sircar Medical College and Hospital, Kolkata. \\ ${ }^{2}$ Assistant Professor, Department of Medicine, North Bengal Medical College. \\ ${ }^{3}$ Resident Medical Officer \& Clinical Tutor, North Bengal Medical College, Sushrutnagar, Darjeeling. \\ ${ }^{4}$ Associate Professor, Department of Medicine, Institute of Post Graduate Medical Education \& Research, Kolkata. \\ ${ }^{5}$ Associate Professor, Department of Medicine, North Bengal Medical College. \\ ${ }^{6}$ Resident Medical Officer, Department of Medicine, R. G. Kar Medical College. \\ ${ }^{7}$ D. M. Cardiology Post Doctorate Trainee, Institute of Post Graduate Medical Education \& Research, Kolkata. \\ ${ }^{8}$ Assistant Professor, Department of Medicine, Calcutta National Medical College and Hospital, Kolkata.
}

\begin{abstract}
There are conflicting data regarding incidence of Opportunistic Infections in newly diagnosed HIV positive patients on ART. In this article, we studied incidence of Opportunistic Infections in newly diagnosed HIV positive in a tertiary care centre in North Bengal after one year of ART. One hundred and twenty patients were followed for one year after initiating ART. The most common opportunistic infections were Tuberculosis, Candidial infection, skin infections and diarrhea. At the baseline, 32 cases were present with tuberculosis (Pulmonary: 10, 6 sputum -ve and 4 sputum +ve, extrapulmonary: 22). Total patients with candidial infections were 15 (Oral: 12, Oesophageal: 3). After the 6 months of followup 13 patients presented with diarrhoea, 8 cases presented with oral candidiasis, 6 cases presented with tuberculosis. At 12 months of followup, 6 patients presented with tuberculosis, 4 cases with oral candidiasis and 3 cases with diarrhoea. Opportunistic infections at baseline were $60.4 \%$ among the study population, while after 6 and 12 months of ART it decreased to $33.7 \%$ and $16.8 \%$ respectively.
\end{abstract}

\section{KEYWORDS}

Opportunistic Infection, HIV patients, Antiretroviral Therapy.

HOW TO CITE THIS ARTICLE: Majumdar BB, Bala BL, Adhikary A, et al. Study of changes in opportunistic infections after one year of antiretroviral therapy in HIV infected patients in a tertiary care centre in North Bengal. J. Evolution Med. Dent. Sci. 2016;5(8):363-365, DOI: 10.14260/jemds/2016/82

\section{INTRODUCTION}

Heterosexual mode of transmission is still the predominant mode of HIV spread in India. Opportunistic Infections (OIs) and associated complications account for a considerable proportion of mortality in such patients. OIs are diseases caused by group of microbial agents in the presence of a compromised host immune system. Over $80 \%$ of OIs are caused by 28 pathogens. The incidence of OIs depends on the level of immune suppression. Following infections which are less common in immunocompetent persons occurred more frequently in HIV infected persons such as tuberculosis, bacterial pneumonia, amoebiasis, leishmaniasis, candidiasis, malaria, etc. HIV positive individuals were 30-50 times more likely to suffer from active TB than HIV negative individuals. ${ }^{[1]}$ Tuberculosis (TB) is the commonest infection among these people and is also the leading cause of death in people living with HIV/AIDS. In India 50-60\% HIV patients develop active T.B. ${ }^{[2,3]}$ Control and prevention of OIs are an integral part in the management of HIV infection. These approaches have reduced morbidity and mortality significantly in recent past.

Financial or Other, Competing Interest: None.

Submission 26-11-2015, Peer Review 28-11-2015,

Acceptance 18-01-2016, Published 28-01-2016.

Corresponding Author:

Dr. Biswadev Basu Majumdar

C/o. Bijan Basu Majumdar

Vill Sebagram, P. O. Debnagar,

PS: Kotwali, Dist,

Jalpaiguri-735102,

West Bengal.

E-mail: dr.biswadev.basu@gmail.com

DOI: $10.14260 /$ jemds/2016/82
In spite of such an important aspect of HIV management, there are limited data regarding the incidence of various OIs in resource limited settings of North Eastern part of our country, particularly North Bengal. We therefore realize the need to conduct such studies to assess the incidences of specific OIs in this part of the country and whether this data is similar to the national data. In this study we analysed data from North Bengal Medical College ART Centre of 120 HIV naïve patients receiving ART for 12 months in respect to the incidences of specific OIs at the start, then at 6 months and at 12 months and the effect of ART on incidences of OIs.

\section{MATERIALS AND METHODS}

This study was conducted at the ART centre of North Bengal Medical College under the Department of General Medicine. HIV/AIDS patients attending Medical Outpatient Department (MOPD) or ART Centre of North Bengal Medical College and Hospital were selected for study. It is a case series analytical study.

\section{Inclusion Criteria}

1. ART naïve HIV positive patients greater than 12 years.

2. First line drug regime approved by NACO.

\section{Exclusion Criteria}

1. Patients with poor adherence.

2. Paediatric patients.

3. Pre-existing IHD, DM, IGT, dyslipidemia at initiation.

NACO guidelines for eligibility criteria of ART therapy were maintained. Patients were selected from the ART register who were started on ART. 
Newly registered patients from January 2010 to January 2011 were taken and each patient was followed up for 1 year for incidences of specific OIs at baseline, 6 months and at 12 months. Patients who had active opportunistic infections were treated and put on Anti-Retroviral Therapy as per protocol. Prophylaxis of other OIs were started as needed. Patients were followed up every month up to 1 year. Opportunistic infections were recorded at start, 6 months and at 12 months.

Data were collected, collated and transferred to Excel Spread sheet (MS Excel 2007) and analysed using IBM-SPSS ver. 16. Chicago. All the statistical significance tests were done assuming Level of Significance at 95\% confidence intervals.

\section{RESULTS AND ANALYSIS}

Here 120 diagnosed case of HIV-infected patient, who attended the ART Centre of North Bengal Medical College and Hospital for ART were selected for study. Relevant history taking, clinical examination and investigations for OIs were done at the baseline after 6 and 12 months. Follow-up data were available for 101 patients at 6 months and 12 months ( 10 patients died, 5 patients were lost to follow-up and 4 were transferred out to the other ART centre). Data from patients who died were lost to follow-up or transferred out to the other ART centre were not included in this analysis. Patients of age group 18 onwards were included as consent could not be attained from guardians of minors.
Analysis of data revealed the following about the Opportunistic Infections

1. The most common opportunistic infection in the study population was Tuberculosis. Candidial infection, skin infections and diarrhoea were the next most common opportunistic infections. At the baseline 32 cases were present with tuberculosis, out of them 10 patients were pulmonary ( 6 were sputum negative and 4 were sputum positive) and 22 patients were extrapulmonary tuberculosis.

2. Total patients with candidial infections were 15 (12 were oral candidial infections and 3 were oesophageal candidiasis).

3. Skin infection was present in 14 patients (Herpes zoster -3 , molluscum contagiosum -2 and others -9 ).

4. After the 6 months of followup, 13 patients presented with diarrhoea, 8 cases presented with oral candidiasis, 6 cases presented with tuberculosis.

5. Finally after 12 months of followup, only 6 patients presented with tuberculosis.

\begin{tabular}{|c|c|c|c|}
\hline $\begin{array}{c}\text { Opportunistic } \\
\text { Infection }\end{array}$ & Base & 6 Month & 12 Month \\
\hline Present & $61(60.4 \%)$ & $34(33.7 \%)$ & $17(16.8 \%)$ \\
\hline Absent & $40(39.6 \%)$ & $67(66.3 \%)$ & $84(83.2 \%)$ \\
\hline Total & $\mathbf{1 0 1 ( 1 0 0 \% )}$ & $\mathbf{1 0 1 ( 1 0 0 \% )}$ & $\mathbf{1 0 1}(\mathbf{1 0 0 \% )}$ \\
\hline
\end{tabular}

Table 1: OIs at baseline, 6 months and 12 months

\begin{tabular}{|c|c|c|c|c|c|}
\hline \multicolumn{3}{|c|}{$\begin{array}{c}\text { Name of Opportunistic } \\
\text { Infections } \\
\end{array}$} & $\begin{array}{c}\text { At base } \\
\text { line }\end{array}$ & $\begin{array}{c}\text { After } \\
6 \text { months }\end{array}$ & $\begin{array}{c}\text { After } \\
12 \text { months }\end{array}$ \\
\hline \multirow{7}{*}{ Tuberculosis } & \multirow{2}{*}{ Pulmonary } & Sputum positive & 4 & 0 & 2 \\
\hline & & Sputum negative & 6 & 1 & 2 \\
\hline & \multirow{5}{*}{ Extrapulmonary } & Pleural effusion & 10 & 3 & 1 \\
\hline & & Abdominal T.B. & 6 & 2 & 1 \\
\hline & & T.B. Lymph node & 3 & 0 & 0 \\
\hline & & T.B. Meningitis & 2 & 1 & 0 \\
\hline & & Skin T.B. & 1 & 0 & 0 \\
\hline \multirow{3}{*}{ Skin infection } & \multicolumn{2}{|c|}{ Molluscum } & 2 & 1 & 0 \\
\hline & \multicolumn{2}{|c|}{ Herpes zoster } & 3 & 1 & 1 \\
\hline & \multicolumn{2}{|c|}{ Others } & 9 & 1 & 2 \\
\hline \multirow{2}{*}{ Candidiasis } & \multicolumn{2}{|c|}{ Oral } & 12 & 8 & 4 \\
\hline & \multicolumn{2}{|c|}{ Oesophageal } & 3 & 0 & 0 \\
\hline \multicolumn{3}{|c|}{ Diarrhoea } & 5 & 8 & 3 \\
\hline \multicolumn{3}{|c|}{ Malaria } & 2 & 2 & 1 \\
\hline \multicolumn{3}{|c|}{ Pneumocystis jiroveci pneumoniae } & 1 & 0 & 0 \\
\hline \multicolumn{3}{|c|}{ Histoplasmosis } & 1 & 0 & 0 \\
\hline \multicolumn{3}{|c|}{ Disseminated Cryptococcus } & 1 & 0 & 0 \\
\hline \multicolumn{3}{|c|}{ Toxoplasma } & 1 & 0 & 0 \\
\hline \multicolumn{3}{|c|}{ Community acquired pneumonia } & 0 & 1 & 0 \\
\hline \multicolumn{3}{|c|}{ HIV-Nephropathy } & 1 & 0 & 0 \\
\hline \multicolumn{3}{|c|}{ Bacterial pneumonia } & 1 & 0 & 0 \\
\hline \multicolumn{3}{|c|}{ Lung abscess } & 1 & 0 & 0 \\
\hline
\end{tabular}




\section{DISCUSSION}

The mean age of the patients in this study was 33.15 HIV sentinel surveillance and HIV Estimation, 2006 in India showed that $88.7 \%$ of HIV were in $15-49$ years of age and a gender ratio of 1.56:1, which is almost equal in this study.

In the present study, the introduction of ART is associated with a dramatic effect in the overall reduction of incidence rates of opportunistic infections of the patients living with HIV/AIDS. These findings are in agreement with various studies that have linked the use of ART therapy to a decline in opportunistic infections in HIV-infected patients. In an investigation realized by Schmidt-Westhausen, et al. in $2000 .{ }^{[4]}$ the prevalence of oral opportunistic infections associated with HIV was analysed before and after beginning ART. A statistically significant reduction in oral candidiasis was observed with a pre-ART incidence rate of $66 \%$, contrasting with one $5.8 \%$ after this therapy was introduced. Other infections such as Molluscum Contagiosum and herpes simplex were observed in $4.9 \%$ and $2.9 \%$ of the cases respectively, before the use of antiretroviral treatment and not observed at all after the implementation of ART.

Brodt et al. in 1997.[5] also found this association. Infections like Pneumocystis Jirovecii Pneumonia (PCP) also fell: from 17.8/100 persons-year in 1992 to 6.4/100 personsyear in 1996; disseminated CMV fell from 14.7/100 persons per year to 3.6/100 persons per year. Talitah MS Candiani, et al.[6] found in the hybrid cohort was conducted from March 1989 to December 2003 that of the total opportunistic infections, $74.2 \%$ occurred in the non-ART group. In the ART group, there were $25.8 \%$ episodes of opportunistic infections recorded. It was also found that of the opportunistic infections diagnosed during ART use, half occurred during the first three months of therapy, during the phase called partial immunological restoration. Extrapulmonary tuberculosis, hepatitis C, toxoplasmosis and visceral leishmaniasis presented respectively, the following pre-ART incidence rates per person per year: $1.7 \%$, (95\% CI: $0.60-3.70), 1.16 \%$ (95\% CI: $0.40-2.70), 0.49 \%$ (95\% CI: $0.06-1.80)$ and $0.48 \%$ (95\% CI: 0.06-1.70), while Nocardiosis, progressive multifocal leukoencephalopathy and tuberculoid variety of Hansen's disease, each had an incidence of $0.24 \%$ (95\% CI: 0.01-1.40\%). None of these infections were identified after the introduction of ART.

Badri M, et al. in 2002.[7] found in their cohort study on effect of highly active antiretroviral therapy on incidence of tuberculosis in South Africa that ART was associated with a lower incidence of tuberculosis (2.4 vs 9.7 cases per 100 patients per year, adjusted rate ratio 0.19 [95\% CI: 0.09-0.38]; $\mathrm{p}<0.0001)$. ART reduced the incidence of HIV associated tuberculosis by more than $80 \%$ (95\% CI: 62-91) in an area endemic with tuberculosis and HIV. The protective effect of ART was greatest in symptomatic patients and those with advanced immune suppression. Girardi E et al. and Jones JL et al.[8] found in their studies from the USA and Italy that the overall tuberculosis risk reduction estimated of $80 \%$ and $92 \%$, respectively. Brodt and colleagues found no significant tuberculosis reduction during a 5-year period, in which ART use in a German cohort increased from 5.7\% to $87.3 \%$. Moreover, although there was a tendency towards a lower risk of tuberculosis with ART use in a study by Santoro-Lopes and
Colleagues from Brazil.[9] the adjusted estimate was not significant. However, only 41 individuals received ART in that study.

The present study found that the benefits of antiretroviral therapy for the management of HIV/AIDS patients have been well established in respect of decreased incidence of opportunistic infections after one year of ART therapy. Current study shows that ART therapy is very effective in reducing incidence of Opportunistic Infections in patients infected with HIV.

\section{CONCLUSION}

Opportunistic Infections are very common in HIV and initiation of ART can reduce their incidence in these patients. The most common opportunistic infection in the study population was Tuberculosis. Candidial infection, skin infections and diarrhea were the next most common opportunistic infections. At the baseline, opportunistic infections were $60.4 \%$ among the study population. After 6 months and 12 months of receiving ART, it was decreased to $33.7 \%$ and $16.8 \%$ respectively.

\section{REFERENCES}

1. Govt. of India (2006), Strategy and Implementation Plan, National AIDS Control Programme Phase III (2007-2012), NACO, Ministry of Health and Family Welfare, New Delhi.

2. Tbcindia.org [homepage on Internet]. New Delhi: Central Tuberculosis Division, Ministry of Health and Family Welfare, Government of India; c2006 [Cited 2006 October 30].

3. Sharma SK, Ahluwalia G. HIV and Tuberculosis. Indian J Chest Dis Allied Sci 2000;42:77-81.

4. Schmidt-Westhausen A, Priepke F, Bergmann FJ, et al. Prognostic and predictive factors in oral cancer: the role of the invasive tumour front. Journal of oral pathology \& medicine 2000;29(7):291-8.

5. Brodt HR, Kamps BS, Gute P, et al. Changing incidence of AIDS-defining illnesses in the era of antiretroviral combinational therapy. AIDS 1997;11(14):1731-8.

6. Candiani TM, Pinto J, Cardoso CA, et al. Impact of highly active antiretroviral therapy (HAART) on the incidence of opportunistic infections, hospitalizations and mortality among children and adolescents living with HIV/AIDS in Belo Horizonte, Minas Gerais State, Brazil. Cadernos de Saúde Pública [Online]. 2007;23(3):1678-4464.

7. Badri M, Wilson D, Wood R, et al. Effect of highly active antiretroviral therapy on the incidence of tuberculosis in South Africa: a cohort study. The Lancet 2002;359:2059-64.

8. Giardi E, Palmeiri F, Cingolani A, et al. Changing clinical presentation and survival in HIV-associated tuberculosis after highly active antiretroviral therapy. JAIDS 2001;26(4):326-31.

9. Santoro-Lopes G, De Pinho AM, Harrison LH, et al. Reduced risk of tuberculosis among Brazilian patients with advanced human immunodeficiency virus infection treated with highly active antiretroviral therapy. Clin infect Dis 2002;34(4):543-46. 